\title{
WHO/ISBRA Study on State and Trait Markers in Alcoholism
}

\author{
Boris Tabakoff, Anders Helander, Kate M. Conigrave, Larry Martinez, Paula L. Hoffman, J. Whitfield, L. Degenhardt, \\ J. Saunders, A. Barón, J. Glanz, and Members of the WHO/ISBRA Study Group
}

This article represents the proceedings of a symposium at the 2000 ISBRA Meeting in Yokohama, Japan. The chair was Boris Tabakoff. The presentations were (1) Overview of the WHO/ISBRA study on state and trait markers in alcoholism, by Boris Tabakoff; (2) Biochemical markers of acute and chronic drinking: Results of the WHO/ISBRA study, by Anders Helander; (3) The impact of country of recruitment and body mass index on biological marker dose-response curves in the WHO/ISBRA Study, by Kate M. Conigrave; (4) Relationship of body water to carbohydrate-deficient transferrin measures, by Larry Martinez; and (5) Platelet adenylyl cyclase activity as a trait marker of alcohol dependence, by Paula L. Hoffman.

Key Words: Alcoholism, State Marker, Trait Marker, CDT, Adenylyl Cyclase, 5-HTOL.

$\mathbf{I}^{\mathrm{N}}$ N 1984, AFTER a significant period of planning and preparation, the WHO/ISBRA Multicenter Study of State and Trait Markers of Alcoholism was initiated. This study encompassed personnel and subjects from five clinical centers located in Sao Paulo (Brazil), Sydney (New South Wales, Australia), Helsinki (Finland), Montreal (Canada), and Sapporo (Japan). Also participating in this study were four diagnostic assay centers: Stockholm (Sweden), Denver, Colorado (USA), Indianapolis, Indiana (USA), and Helsinki (Finland). Additionally, a data repository center located at NIAAA in Bethesda, Maryland, provided for the study, data entry, data review, and certain analysis functions.

The symposium on the WHO/ISBRA collaborative project brought together individuals from the various clinical and diagnostic assay centers for an initial review of the data that have been gathered in this study. The collection of subjects was completed in spring 1999, and since that time, data have been collated and made available for analysis to the participating centers. Data on 1863 subjects from the five participating clinical centers are available for analysis. The available data include the following: sociodemographic information on the subjects; lifetime and past 30 day occurrence of medical conditions (which include quantity and frequency of prescription drug use during the last 7 days and during the last 30 days); beverage-specific frequency and quantity of drinking during the past 30 days and the period when the subject was drinking the most; symptoms experienced with various levels of drinking; information that allows for ICD-10 and DSM-IV diagnosis of alcohol abuse, dependence, and withdrawal syndromes; alcohol treatment history; alcoholism subtypes; history

From the University of Colorado Health Sciences Center (BT, LM, AB, $J G, P L H)$, Denver, Colorado; Karolinska Hospital (AH), Stockholm, Sweden; and Royal Prince Alfred Hospital (KMC, JW, LD, JS), Sydney, Australia. Received for publication January 11, 2001; accepted January 11, 2001.

Reprint requests: Boris Tabakoff, PhD, Department of Pharmacology, University of Colorado Health Sciences Center SOM, 4200 E. Ninth Ave., C-236, Denver, CO 80262; Fax: 303-315-0708; E-mail: boris.tabakoff@uchsc.edu

Copyright (c) 2001 by the Research Society on Alcoholism. of smoking and illicit drug use; history of major depression and antisocial behavior; treatment for mental or emotional problems; and family history of alcohol problems or alcoholism, major depression, drug abuse and/or dependence, antisocial personality disorder, and other psychiatric disorders in the biological parents, siblings, aunts, uncles, and grandparents.

This information has been obtained with a structured interview instrument that was developed for this study in concert with development of the Alcohol Use Disorders and Associated Disabilities Interview Schedule by NIAAA. The instrument has been translated into Finnish, Japanese, French, German, and Portuguese for use by the various clinical centers involved in this study.

Table 1 details some of the demographic variables that have been collected on the subjects. The $\kappa$ values of the major data elements that appear in the WHO/ISBRA interview schedule range from a low of 0.55 for items such as DSM-IV diagnosis of marijuana dependence to values of 1.0 for family history of alcoholism in the biological mother. Values of 0.70 to 0.90 for 20 alcohol experiences in the respondent and values of 0.60 to 0.80 for DSM-IV and ICD-10 diagnosis of alcohol abuse and dependence have been determined.

The presentations at the symposium focused on some traditional and newly identified biochemical measures of acute alcohol consumption, and one presentation focused on platelet adenylyl cyclase activity, which seems to be both a state and a trait marker for alcoholism.

FACTORS THAT INFLUENCE CDT, GGT, AND AST LEVELS: A MULTICENTER COLLABORATIVE STUDY

K. Conigrave, J. Whitfield, L. Degenhardt, J. Saunders, and the Members of the WHO/ISBRA Study Group

Dr. Conigrave and her colleagues examined the value of carbohydrate-deficient transferrin (CDT) as a marker for excessive alcohol consumption in the subject population collected in the WHO/ISBRA Study of State/Trait Markers in Alcoholism. They examined various factors that may influence levels of CDT and the levels of liver enzymes, 
Table 1. Demographic Variables $(n=1863)$

\begin{tabular}{|c|c|c|}
\hline & Men & Women \\
\hline \multicolumn{3}{|l|}{ Race, $n$} \\
\hline White & 974 & 431 \\
\hline Black & 53 & 48 \\
\hline Asian & 156 & 98 \\
\hline Other & 63 & 37 \\
\hline Age & $37.51 \pm 11.80$ & $37.04 \pm 12.29$ \\
\hline \multicolumn{3}{|l|}{ Alcohol dependence, $n$} \\
\hline Nondependent & 631 & 387 \\
\hline Currently dependent & 155 & 50 \\
\hline Lifetime dependent & 463 & 177 \\
\hline \multicolumn{3}{|l|}{ Alcohol consumption, g/month } \\
\hline Total EtOH as beer & $1373.01 \pm 1894.96$ & $840.80 \pm 1327.33$ \\
\hline Total EtOH as wine & $338.51 \pm 1021.70$ & $264.02 \pm 637.57$ \\
\hline Total EtOH as liquor & $689.15 \pm 1593.87$ & $434.11 \pm 1305.96$ \\
\hline Total EtOH & $2379.54 \pm 2822.36$ & $1523.15 \pm 1997.27$ \\
\hline Lifetime marijuana abuse, $n(\%)$ & $74(6.0 \%)$ & $31(5.0 \%)$ \\
\hline \multicolumn{3}{|l|}{ Smoking status, $n(\%)$} \\
\hline Nonsmoker & $416(33.5 \%)$ & 247 (40.6\%) \\
\hline Ex-smoker & $229(18.5 \%)$ & $85(14.0 \%)$ \\
\hline Current smoker & $595(48.0 \%)$ & $276(45.40 \%)$ \\
\hline Depression DSM-IVa,$n(\%)$ & $154(12.3 \%)$ & $140(22.8 \%)$ \\
\hline Family history alcoholism ${ }^{a}, n(\%)$ & $526(46.8 \%)$ & $311(53.8 \%)$ \\
\hline
\end{tabular}

${ }^{a}$ The percentages represent the percentage within each sex. For example, $6 \%$ $(n=74)$ of the men and $5 \%(n=31)$ of the women are lifetime marijuana abusers.

$\gamma$-glutamyltransferase (GGT), and aspartate amino transferase (AST). Dr. Conigrave documented how drinking level, sex, age, body mass index, and country of recruitment affected the relationship between CDT and alcohol consumption. Dr. Conigrave and her colleagues reported that each marker (CDT, GGT, and AST) increased with increasing alcohol consumption. But, as reported previously, levels of CDT and GGT were only weakly correlated.

In men, the correlation between marker levels and alcohol consumption was strongest for CDT, followed by GGT and then AST. In contrast, in women, GGT was more strongly correlated with alcohol consumption than was CDT, which performed only slightly better than AST. A history of alcohol dependence at some stage in a subject's life did not significantly affect marker levels in drinkers who consumed up to 80 $\mathrm{g} /$ day. In the open-ended category of persons drinking $80 \mathrm{~g}$ or more ethanol per day, those with a history of dependence tended to have a higher marker level, but this may have simply reflected higher alcohol consumption.

In men, CDT was a significantly more accurate marker of heavy drinking ( $>90 \mathrm{~g} /$ day) than it was of less heavy drinking (50-89 g/day) by receiver operating characteristic (ROC) analysis. CDT performed significantly less well in women than in men, whereas GGT had a comparable performance in men and in women. CDT was not found to be a significantly better marker than GGT as a single test of excessive alcohol consumption in this population.

The combined use of GGT and CDT was examined. As expected, the combination of the two tests, by using standard cutoff points and where a positive result in either test constitutes an overall positive result, was associated with increased sensitivity compared with either test alone, but with some loss of specificity. In men, the specificity fell below $70 \%$ for the combination of tests, whereas in women it remained above $80 \%$.
Persons younger than 20 years $(n=77)$ showed minimal association between CDT or GGT levels and alcohol consumption. In general, CDT, GGT, and AST marker levels all increased with age. High body mass index was associated with increased GGT levels, particularly in the highest alcohol consumption category. In contrast, CDT levels were not increased by obesity. There was a tendency for subjects recruited from Sapporo, Japan, to have lower CDT levels, whereas those recruited from Sao Paulo, Brazil, tended to have higher liver enzyme levels for any reported level of alcohol use. The overall analysis showed that CDT and GGT levels are affected by sex, age, and body mass index in addition to alcohol use.

The analysis did not reveal CDT as a significantly better single test of alcohol use than GGT; however, this analysis did not examine particular situations in which CDT potentially can offer greater advantage, such as in monitoring treatment progress in alcohol dependence or monitoring alcohol use in patients with a high prevalence of liver disease or other factors known to elevate GGT levels. The results showed that obesity can elevate GGT levels, although it does not increase CDT. The results also suggested a role for the combined use of CDT and GGT, although specificity inevitably will be reduced somewhat.

The reason for lower CDT levels in subjects from Japan was not clear and is worthy of further analysis. The higher liver enzyme levels in the Sao Paulo population conceivably could have been caused by a higher background prevalence of viral hepatitis, but this question also needs to be examined further.

\section{THE EFFECT OF TOTAL BODY WATER ON CDT AS A MARKER FOR HARMFUL ALCOHOL CONSUMPTION}

\section{D. Martinez, A. Barón, A. Helander, K. Conigrave, B. Tabakoff, and the Members of the WHO/ISBRA Study Group}

Mr. Martinez presented additional information about factors that influence the use of CDT as a measure of alcohol consumption and/or alcohol dependence. Mr. Martinez stressed the influence of body water on the diagnostic performance of CDT. It is well established that ethanol's volume of distribution is nearly equivalent to an individual's total body water (TBW) volume, and that sex, age, height, and weight are the primary determinants of an individual's TBW (Watson, 1989)

Women have lower TBW due to their smaller stature and lower percentage of lean body mass. Thus, for any given quantity of alcohol consumed, women would be expected to achieve higher blood alcohol concentrations compared with men. Individual factor statistics for ANOVA analysis that compared models before and after TBW was accounted for are shown in Table 2. The effect on CDT levels due to sex and age was lost when differences in TBW were taken into account and, instead, an interaction between CDT and TBW became evident $(t=-7.5, p<0.001)$.

Figure 1 shows the relationship between mean CDT levels and alcohol consumption by expressing CDT in concentration units or total CDT, which is adjusted for TBW 
Table 2a. Individual Factor Statistics for ANOVA Analysis: Model Without Total Body Water

\begin{tabular}{|c|c|c|c|c|c|c|}
\hline \multicolumn{5}{|c|}{ Dependent variable: CDT } & \multicolumn{2}{|c|}{$95 \%$ Confidence interval } \\
\hline Parameter & Beta & SE & $t$ & Sig. & Lower bound & Upper bound \\
\hline Intercept & 16.412 & 1.617 & 10.150 & .000 & 13.240 & 19.585 \\
\hline Male & -3.753 & .946 & -3.968 & .000 & -5.609 & -1.897 \\
\hline Female & $0^{a}$ & & & & & \\
\hline White & 1.247 & 1.148 & 1.086 & .278 & -1.006 & 3.499 \\
\hline Black & 3.701 & 1.814 & 2.040 & .042 & .142 & 7.260 \\
\hline Asian & $0^{a}$ & & & & & \\
\hline Nonsmoker & -2.761 & .835 & -3.308 & .001 & -4.399 & -1.124 \\
\hline Ex-smoker & -3.797 & .974 & -3.897 & .000 & -5.709 & -1.886 \\
\hline Current smoker & $0^{a}$ & & & & & \\
\hline Subject's age & 8.663E-02 & .030 & 2.933 & .003 & 2.869E-02 & .145 \\
\hline Consumption, g/day & 2.387E-02 & .009 & 2.554 & .011 & 5.536E-03 & 4.221E-02 \\
\hline Male* consumption & 4.412E-02 & .010 & 4.300 & .000 & 2.399E-02 & 6.426E-02 \\
\hline Female* consumption $^{*}$ & $0^{a}$ & & & & & \\
\hline
\end{tabular}

a This parameter is set to zero because it is redundant.

Table 2b. Individual Factor Statistics for ANOVA Analysis: Model With Total Body Water

\begin{tabular}{|c|c|c|c|c|c|c|}
\hline \multicolumn{5}{|c|}{ Dependent variable: CDT } & \multicolumn{2}{|c|}{ 95\% Confidence interval } \\
\hline Parameter & Beta & SE & $t$ & Sig. & Lower bound & Upper bound \\
\hline Intercept & 24.637 & 3.383 & 7.282 & .000 & 17.999 & 31.274 \\
\hline Male & -.481 & 1.494 & -.322 & .747 & -3.142 & 2.450 \\
\hline Female & $0^{a}$ & & & & & \\
\hline White & 3.079 & 1.120 & 2.750 & .006 & .882 & 5.276 \\
\hline Black & 3.929 & 1.716 & 2.290 & .022 & .563 & 7.296 \\
\hline Asian & $0^{a}$ & & & & & \\
\hline Nonsmoker & -1.799 & .783 & -2.298 & .022 & -3.335 & -.293 \\
\hline Ex-smoker & -2.243 & .919 & -2.441 & .015 & -4.046 & -.441 \\
\hline Current smoker & $0^{a}$ & & & & & \\
\hline Subject's age & 1.661E-02 & .028 & .583 & .560 & $-3.92 \mathrm{E}-02$ & 7.245E-02 \\
\hline Consumption, g/day & .224 & .028 & 8.059 & .000 & .170 & .279 \\
\hline Male* consumption & .113 & .014 & 8.294 & .000 & 8.593E-02 & .139 \\
\hline Female $^{\star}$ consumption & $0^{a}$ & & & & & \\
\hline
\end{tabular}

a This parameter is set to zero because it is redundant.

by multiplying CDT by TBW. When men and women are compared, in Fig. 1a, CDT levels in non-alcohol-consuming and moderate-alcohol-consuming women were significantly higher compared with men. In contrast, if one adjusts CDT levels for TBW (Fig. 1b), the difference in basal CDT.TBW level when men and women are compared is no longer evident. As consumption increases to a moderate level, CDT·TBW levels in men begin to increase, whereas CDT.TBW in women remains constant. At heavy consumption levels ( $>30 \mathrm{~g} /$ day), CDT·TBW levels in men are significantly higher than at baseline, whereas the levels in women are more modestly elevated (Fig. 1b).

Using ROC analysis, Mr. Martinez and his colleagues examined the operating characteristics of CDT as a marker of alcohol consumption. CDT was expressed in terms of units per liter, or as CDT·TBW. Consumption thresholds that ranged from 30 to $80 \mathrm{~g} /$ day were tested. Across all drinking levels, ROC analysis returned a better sensitivity and specificity and a significantly larger area under the curve for men compared with women. Also apparent was that adjusting CDT values for individual differences in TBW improved the operating characteristics for women but not for men. In other words, in the female subjects, variations in TBW significantly impact the CDT alcoholdose response and may explain the poor operating characteristics observed in female subjects.
Mr. Martinez concluded that the effect of sex was influenced significantly by body water, particularly in women. Mr. Martinez stated that adjustment for TBW revealed a relationship between TBW and CDT that is dependent on an alcohol/ TBW interaction. Enhanced sensitivity of CDT when TBW is taken into account in women (while males remain constant) can be interpreted to mean that, for women, total body water changes secondary to alcohol consumption are a better predictor of elevated CDT than is alcohol consumption itself.

BIOCHEMICAL TESTS FOR ACUTE ALCOHOL CONSUMPTION: RESULTS OF THE WHO/ISBRA STUDY

\section{A. Helander and Members of the WHO/ISBRA Study Group}

Dr. Helander focused on the use and performance of several diagnostic tests that monitor the recency of alcohol intake. The markers of acute alcohol consumption examined by Dr. Helander and his group included the concentrations of methanol and ethanol in plasma and 5-hydroxytryptophol in urine (expressed as the ratio to 5-hydroxyindole-3-acetic acid, 5HTOL/5HIAA). No marked differences in the baseline urinary $5 \mathrm{HTOL} / 5 \mathrm{HIAA}$ ratio was observed in the nondrinkers recruited at the five clinical centers and, therefore, Dr. Helander used the accepted cutoff of $15 \mathrm{pmol} / \mathrm{nmol}$ across the study population. The subjects in the study were classified into one of four categories, as described earlier (Helander et al., 
Consumption gms/day and CDT units (gm/L).

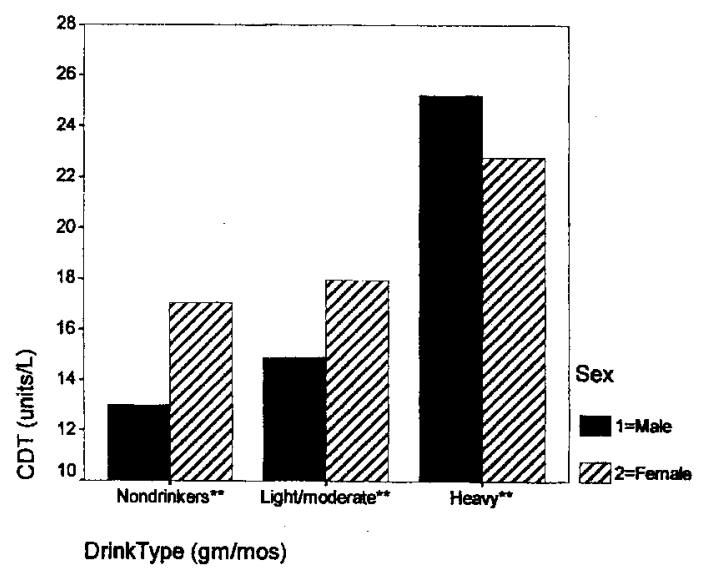

Consumption and CDT values adjusted for total body water.

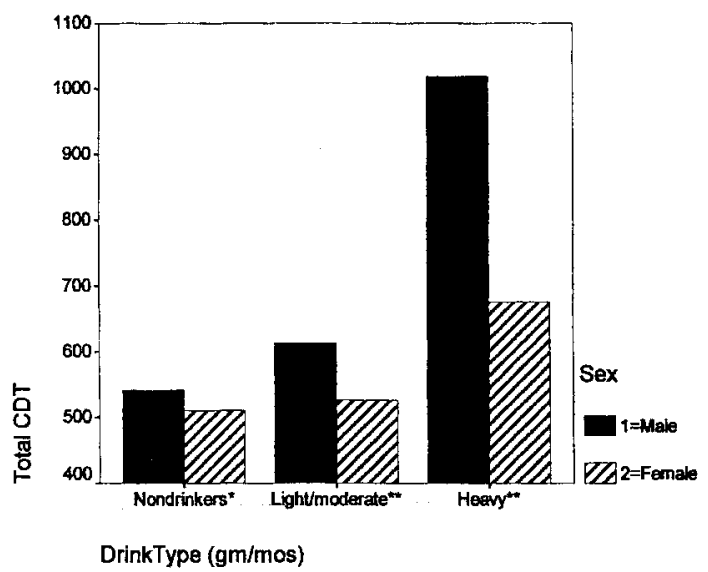

Fig. 1 (a) Consumption in grams per day and CDT units (g/liter); (b) consumption and CDT values adjusted for total body water.

1997): nondrinker, light/moderate drinker, heavy drinker, or alcohol-dependent individual.

Within the four categories of drinkers, a large number of individuals reported that they consumed no ethanol during the last 24 or more hours. However, a low number of those classified as nondrinkers still showed positive test results with the short-term alcohol intake markers, although no alcohol intake was reported by these individuals. Accordingly, $6(1.4 \%)$ showed the presence of low levels of ethanol in plasma (range 1-9 mmol/liter; median 2.5), $22(5.3 \%)$ showed a positive 5HTOL/5HIAA ratio (range 16-220 $\mathrm{pmol} / \mathrm{nmol}$; median 42$)$, and $12(3.0 \%)$ showed a methanol concentration that exceeded $65 \mu \mathrm{mol} / \mathrm{liter}$.

In the light/moderate drinkers who reported no alcohol intake in the last 24 or more hours, $25(3.7 \%)$ showed the presence of ethanol in plasma (range 1-18 mmol/liter; median 1), 69 (10.1\%) showed a positive urinary 5HTOL/ 5HIAA ratio (range $15-725 \mathrm{pmol} / \mathrm{nmol}$; median 26), and 41 $(7.3 \%)$ showed an elevated methanol concentration in plasma (range 66-319 $\mu \mathrm{mol} /$ liter; median 94).
In the heavy drinkers, $45(13.9 \%)$ showed the presence of ethanol in plasma (range 1-44 mmol/liter; median 8), 129 $(38.7 \%)$ showed a positive urinary 5HTOL/5HIAA ratio (range 15-1671 pmol/nmol; median 83), and 66 (21.7\%) showed an elevated methanol concentration in plasma (range 66-1017 $\mu \mathrm{mol} /$ liter; median 146).

In those classified as alcohol dependent (some of whom were undergoing treatment at the time of sampling), 19 $(6.1 \%)$ showed the presence of ethanol in plasma (range 1-35 $\mathrm{mmol} /$ liter; median 4$), 82(25.2 \%)$ showed a positive urinary 5HTOL/5HIAA ratio (range 15-792 pmol/nmol; median 27), and $36(13.3 \%)$ showed an elevated methanol concentration in plasma (range 67-1130 $\mu \mathrm{mol} /$ liter; median 163).

In those who reported any alcohol intake within $12 \mathrm{hr}$ before sampling, $25.8 \%$ showed the presence of ethanol (range 1-34 mmol/liter; median 11.5), 56\% showed a positive urinary $5 \mathrm{HTOL} / 5 \mathrm{HIAA}$ ratio (range $15-1492 \mathrm{pmol} / \mathrm{nmol}$; median 165), and $41.7 \%$ showed an elevated methanol concentration (range 66-1130 $\mu \mathrm{mol} /$ liter; median 163). In those who admitted drinking between 12 and $24 \mathrm{hr}$ before sampling, $8.1 \%$ showed the presence of ethanol, $31.6 \%$ had a positive $5 \mathrm{HTOL} /$ 5HIAA ratio, and $16.1 \%$ had an elevated methanol level.

Also, in those who denied any intake of alcohol within the last $48 \mathrm{hr}$, several subjects showed abnormal test results with the markers of acute alcohol intake. The urinary 5HTOL/ 5HIAA ratio was the most, and ethanol the least, sensitive test.

In all five clinical center populations, the test of acute alcohol consumption performed quite similarly, with the urinary 5HTOL/5HIAA ratio being most sensitive. Accordingly, the sensitivity for any drinking within the last $24 \mathrm{hr}$ according to self-reports ranged between $23 \%$ and $57 \%$ (mean $41 \%$ ) for the urinary 5HTOL/5HIAA ratio, $16 \%$ and $29 \%$ (mean 24\%) for methanol in plasma, and $0 \%$ and $24 \%$ (mean $12 \%$ ) for ethanol in plasma.

\section{PLATELET ADENYLYL CYCLASE ACTIVITY AS A TRAIT MARKER OF ALCOHOL DEPENDENCE}

\section{P. L. Hoffman, J. Glanz, L. D. Martinez, and the Members of the WHO/ISBRA Study Group}

Dr. Hoffman discussed the use of platelet adenylyl cyclase activity as either a state or a trait marker or marker of alcohol use and/or alcohol dependence. Adenylyl cyclase activity in platelets and other blood cells has been shown in a number of studies to be lower in alcohol-dependent individuals than in control subjects (Diamond et al., 1987; Tabakoff et al., 1988; Waltman et al., 1993). To further assess the validity of low platelet adenylyl cyclase activity as a trait and/or state marker for alcoholism, Dr. Hoffman and her group analyzed the platelet adenylyl cyclase activity in the subjects recruited for the WHO/ISBRA Multicenter Study on State and Trait Markers of Alcoholism. When the total data set from all the centers associated with the WHO/ISBRA study was analyzed, no significant difference in platelet adenylyl cyclase activity between alcohol-dependent and nondependent subjects was noted. The analysis, however, noted that all measured platelet 
adenylyl cyclase activities (basal, fluoride-stimulated, guanine nucleotide-stimulated, forskolin-stimulated) tended to be higher in recent drinkers than in abstinent individuals. On the other hand, even after this factor seemed to be accounted for by analyzing data from individuals who reported 7 days of abstinence before testing, activity was not significantly lower in platelets of alcohol-dependent individuals in this sample.

Dr. Hoffman indicated that there are a number of possible explanations for this finding. Statistical analysis revealed, for instance, that there was a significant influence of site on the results. One can consider that the self-report of abstinence may be more or less reliable in different sites (see presentation by Dr. Helander), and/or that in some populations or individuals, the duration of abstinence may need to be longer than in others to observe lower adenylyl cyclase activity in alcohol-dependent subjects. Recent analysis suggested that adenylyl cyclase activity may continue to decrease for as long as 21 days after cessation of heavy drinking in some individuals. Furthermore, the initial analysis was carried out by using DSM-IV criteria for alcohol dependence, without further characterizing possible subtypes of alcoholism. If low platelet adenylyl cyclase is associated with particular subtypes of alcoholism, and if the proportion of these subtypes differs among the sites, the results could be confounded. Various other factors, which include (but are not limited to) drug use, type of alcohol used, sex, and family history of alcoholism, may differ among sites and influence the results. Therefore, Dr. Hoffman stated that it will be necessary to perform further analyses on the combined data, as well as on the data from the individual sites, to determine whether platelet adenylyl cyclase activity is a widely applicable trait marker for alcohol dependence.

Investigators from the Collaborative Study on the Genetics of Alcoholism (COGA) previously reported an association between a phenotype for severity of alcoholism and a microsatellite marker, on chromosome 16 (Foroud et al., 1998). The gene for a particular adenylyl cyclase isoform, Type IX (AC9), is localized within the same region of chromosome 16 as the microsatellite marker (Hacker et al., 1998). Because AC9 is a very widely expressed isoform of adenylyl cyclase (Premont et al., 1996), it is likely to be present in platelets and other blood cells. Dr. Hoffman and her group searched for polymorphisms in the gene for AC9 to determine associations with the phenotype of alcohol dependence. A polymorphic trinucleotide repeat sequence was found in an intron of the AC9 gene. Subjects $(n=408)$ from the WHO/ISBRA study then were genotyped for this polymorphism. An AC9 genotype was associated $(p<0.06)$ with the DSM-IV diagnosis of alcohol dependence. The allele that appeared to be associated with the diagnosis of alcoholism contained eight repeats of the trinucleotide sequence. It has yet to be determined whether this intronic polymorphism affects the function of adenylyl cyclase, that is, adenylyl cyclase activity in platelets. However, the association between the genetic polymorphism and the diagnosis of alcohol dependence is intriguing when one considers that the subjects were classified only on the basis of DSM-IV criteria but were not yet classified by subtypes of alcoholism such as severity and comorbidity. It is important to reiterate that the association found in the Collaborative Study on the Genetics of Alcoholism was with the phenotype of severity of alcoholism and not simply of alcohol dependence (Foroud et al., 1998).

To date, results indicate that, in some settings, platelet adenylyl cyclase activity may represent a trait marker for a predisposition to alcoholism. In all settings, however, platelet adenylyl cyclase activity is elevated by recent heavy alcohol consumption. The WHO/ISBRA database contains many measures of alcohol intake and other characteristics of the subject, which include information on genotypes. Dr. Hoffman stated that further studies will be pursued, by using this information, to generate a more definitive analysis of the utility of platelet adenylyl cyclase activity as a trait marker for alcoholism in various populations.

In conclusion, the symposium on the progress of the WHO/ISBRA Multicenter Study on State and Trait Markers of Alcoholism produced an intriguing initial look at data gathered in the first worldwide study on the early identification of individuals at risk for developing alcohol dependence. The development of reliable and valid markers to assess the level and frequency of alcohol intake and genetic markers that indicate predisposition to alcoholism would increase the prospect of developing favorable treatment modalities and reducing health care costs. Further analysis of the large volume of data collected in this study will continue to generate valuable information.

\section{REFERENCES}

Diamond I, Wrubel B, Estrin W, Gordon A (1987) Basal and adenosine receptor-stimulated levels of cAMP are reduced in lymphocytes from alcoholic parents. Proc Natl Acad Sci USA 84:1413-1416.

Foroud T, Bucholz KK, Edenberg HF, Goate A, Neuman RJ, Porjesz B, Koller DL, Rice J, Reich T, Bierut LJ, Cloninger CR, Nurnberger JI Jr, Li T-K, Conneally PM, Tishfield JA, Crowe R, Hesselbrock V, Schuckit M, Begleiter H (1998) Linkage of an alcoholism-related severity phenotype to chromosome 16. Alcohol Clin Exp Res 22:2035-2043.

Hacker BM, Tomlinson JE, Wayman GA, Sultant R, Chan G, Villacres E, Distech C, Storm DR (1998) Cloning, chromosomal mapping, and regulatory properties of the human type 9 adenylyl cyclase (ADCY9). Genomics 50:97-104.

Helander A, Tabakoff B, and members of the WHO/ISBRA Study Clinical Centers (1997) Biochemical markers of alcohol use and abuse: Experiences from the pilot study of the WHO/ISBRA collaborative project on state and trait markers of alcohol. Alcohol Alcohol 32:113-144.

Premont RT, Matsuoka I, Mattei MG, Pouille Y, Defer N, Hanoune J (1996) Identification and characterization of a widely expressed form of adenylyl cyclase. J Biol Chem 271:13900-13907.

Tabakoff B, Hoffman PL, Lee JM, Saito T, Willard B, DeLeon-Jones F (1988) Differences in platelet enzyme activity between alcoholics and nonalcoholics. N Engl J Med 318:134-139.

Waltman C, Levine MA, McCaul ME, Svikis DS, Wand GS (1993) Enhanced expression of the inhibitory protein $\mathrm{G}_{\mathrm{i}} 2$ alpha and decreased activity of adenylyl cyclase in lymphocytes of abstinent alcoholics. Alcohol Clin Exp Res 17:315-320.

Watson PE (1989) Total body water and blood alcohol levels: Updating the fundamentals, in Human Metabolism of Alcohol (Crow KE, Blatt RD eds), pp 41-55. CRC Press, Boca Raton, FL. 